\title{
Lifestyle and Environmental Factors in Multiple Sclerosis
}

\author{
Lars Alfredsson ${ }^{1}$ and Tomas Olsson ${ }^{2}$ \\ ${ }^{1}$ Institute of Environmental Medicine, Karolinska Institutet, Stockholm, Sweden; and Centre for Occupation \\ and Environmental Medicine, Stockholm County Council, Stockholm 17177, Sweden \\ ${ }^{2}$ Neuroimmunology Unit, Center for Molecular Medicine, Karolinska Hospital, Solna, \\ 17176 Stockholm, Sweden \\ Correspondence: tomas.olsson@ki.se
}

\begin{abstract}
Lifestyle and environmental factors potently influence the risk of multiple sclerosis (MS), because genetic predisposition only explains a fraction of the risk increase. There is strong evidence for associations of Epstein-Barr virus (EBV) infection, smoking, sun exposure/ vitamin $\mathrm{D}$, and adolescent obesity to risk of MS. There is also circumstantial evidence on organic solvents and shift work, all associate with greater risk, although certain factors like nicotine, alcohol, and a high coffee consumption associate with a reduced risk. Certain factors, smoking, EBV infection, and obesity interact with human leukocyte antigen (HLA) risk genes, arguing for a pathogenic pathway involving adaptive immunity. There is a potential for prevention, in particular for people at greater risk such as relatives of individuals with MS. All of the described factors for MS may influence adaptive and/or innate immunity, as has been argued for MS risk gene variants.
\end{abstract}

ifestyle/environmental factors may act many Lyears before clinical onset, which complicates epidemiologic studies aiming to identify risk factors. Thus, a subclinical phase of many years is supported by the fact that many individuals at clinical onset have several lesions that are seen detected through magnetic resonance imaging (MRI), and they seek health care (Marrie et al. 2013) and report chronic fatigue (Hughes et al. 2013) more often than controls in the years before diagnosis and also reproduce less often than controls in the years before diagnosis (Nielsen et al. 2011; Hedstrom et al. 2014c). The field of multiple sclerosis (MS) epidemiology has widened during the last few years since the time of previous extensive reviews on associations of Epstein-Barr virus (EBV) infection, vitamin $\mathrm{D} /$ sun exposure, and smoking with MS (Ascherio et al. 2012; Lucas et al. 2015). It is therefore timely to review the field, incorporating further developments such as interactions with MS risk genes, and some other factors, which more recently have been identified as candidates for influence on MS risk.

MS is a complex disease for which risk gene variants and lifestyle/environmental factors are both important. Previous studies of the heritability of MS have yielded a familial recurrence relative risk for siblings $(\lambda)$ of 16.8 (O'Gorman et al. 2013). Recent population-based studies

Editors: Howard L. Weiner and Vijay K. Kuchroo

Additional Perspectives on Multiple Sclerosis available at www.perspectivesinmedicine.org

Copyright (C) 2019 Cold Spring Harbor Laboratory Press; all rights reserved; doi: 10.1101/cshperspect.a028944

Cite this article as Cold Spring Harb Perspect Med 2019;9:a028944 
have estimated a $\lambda$ of 7 , indicating a much lower importance of genetic predisposition, highlighting further the role of lifestyle and environmental influences (Westerlind et al. 2014, 2015). Furthermore, there is a latitude gradient (Simpson et al. 2011), and migration studies show risk of MS depends on the age of migration. Those migrating from a low-risk country to a high-risk country before adolescence show a MS risk more similar to that of the high-risk country (Gale and Martyn 1995; Ahlgren et al. 2010, 2012; Berg-Hansen et al. 2015). In the last few decades, there has been a noticeable increase in MS in most countries. Although genes do not change over time, lifestyle and environmental factors do. The immune repertoire, likely to be important for MS, is largely driven by nonheritable factors (Brodin et al. 2015). In addition, we have used the Swedish multigeneration registry and investigated the diagnoses of parents of MS patients. Although there is a great deal of comorbid conditions among MS patients with regard to other inflammatory diseases, the presence of these conditions within the parent generation is much lower, apart from MS, with the expected transmission risk of 5\% (Roshanisefat et al. 2012), consistent with the idea that inflammatory comorbidities are not entirely caused by sharing of genes, but rather lifestyle and environmental factors, or provoked by MS itself. Indeed, only a minority of the non-human leukocyte antigen (HLA) genes in MS are shared with other inflammatory diseases, and effects of single variants may regulate different diseases in opposite directions (Sawcer et al. 2011).

Still, MS risk genes are important. In particular, the class II and I genes are relevant. These encode for molecules that present antigens to $\mathrm{CD}^{+}{ }^{+}$and $\mathrm{CD}^{+}{ }^{+} \mathrm{T}$ lymphocytes. In MS, there is a striking association with the class II variant $H L A-D R B 1^{*}$ 15:01 (odds ratio $[\mathrm{OR}]=\sim 3$ ). HLA$A^{*} 02$, a class I variant, is noted for providing protection $(\mathrm{OR}=\sim 0.6)$. Combined, minus $H L A-A^{*} 02$ and plus $D R B 1^{*} 15: 01$ equals an OR of 5 (Brynedal et al. 2007; Sawcer et al. 2011; Beecham et al. 2013; Moutsianas et al. 2015). Traditionally, the genetic and epidemiological fields have worked separately. In this review, we have aimed to elucidate the complicated picture of disease initiation as it relates to lifestyle/environmental factors, in particular in the context of the HLA class I and II genes, which are the most strongly associated loci to MS. In assessing interaction between various causal factors, we used "departure from additivity of effects" as a criterion (often referred to as additive interaction) (Rothman 2008), which if present indicates the action of the two factors in the same biological pathway. Basically, interaction presents when risk of disease development among people exposed to both causal factors is greater than what one would expect based on the sum of the absolute effects attributed to each factor.

The lifestyle/environmental MS-associated factors include EBV infection, exposure to tobacco smoke and organic solvents, obesity in adolescence, limited sun exposure/low vitamin $\mathrm{D}$, night shift work, all associated with increased risk. Risks that may be associated with lower risk are oral tobacco, high coffee consumption, and alcohol consumption (Table 1). One note of caution: results from observational epidemiologic studies need to be evaluated taking different possible sources of systematic errors into consideration, because observed estimates of association may be affected by biases that can influence results such as (1) reverse causation meaning that the disease is causing the association; (2) confounding factors not considered or confounding factors improperly addressed (e.g., residual confounding) in analytic models; (3) differential misclassification of lifestyle/ environmental factors (e.g., because of recall bias); and (4) selection bias. In the following, we discuss distinct lifestyle and environmental factors.

\section{EPSTEIN-BARR VIRUS}

Multiple infectious agents have been suggested to play a role in MS, with a single factor that has persisted to be highly interesting and for which there is an extensive literature, which is EBV. Because it has been difficult to establish a causal relationship, the casual role of EBV is still debated. However, the collective circumstantial evidence is compelling. Individuals who have had 
Table 1. Summary of established and tentative lifestyle/environmental factors and their potential interaction with multiple sclerosis (MS) human leukocyte antigen (HLA) risk genes

\begin{tabular}{|c|c|c|c|c|c|}
\hline Factor & OR & $\begin{array}{l}\text { HLA gene } \\
\text { interaction }\end{array}$ & $\begin{array}{c}\text { Combined } \\
\text { OR }\end{array}$ & $\begin{array}{c}\text { Effect mainly during } \\
\text { adolescence }\end{array}$ & $\begin{array}{l}\text { Immune system } \\
\text { implied }\end{array}$ \\
\hline Smoking & $\sim 1.6$ & + & 14 & No & + \\
\hline EBV serology & $\sim 3.6$ & + & $\sim 15$ & Yes & + \\
\hline Vitamin $\mathrm{D}<50 \mathrm{~nm}$ & $\sim 1.4$ & No & - & Probably & + \\
\hline $\begin{array}{l}\text { Adolescent obesity/ } \\
\quad \text { BMI }>27\end{array}$ & $\sim 2$ & + & $\sim 15$ & Yes & + \\
\hline Night work & $\sim 1.7$ & No & - & Yes & + \\
\hline Low sun exposure & $\sim 2$ & No & - & Probably & + \\
\hline $\begin{array}{l}\text { Infectious } \\
\text { mononucleosis }\end{array}$ & $\sim 2$ & + & 7 & Yes & + \\
\hline Passive smoking & $\sim 1.3$ & + & 6 & No & + \\
\hline Oral tobacco/nicotine & 0.5 & nd & - & Unknown & + \\
\hline Alcohol & $\sim 0.6$ & nd & - & Unknown & + \\
\hline Coffee & $\sim 0.7$ & nd & - & Unknown & + \\
\hline
\end{tabular}

OR, Odds ration; EBV, Epstein-Barr virus; BMI, body mass index; nd, not determined.

clinically overt infectious mononucleosis (IM) have more than a twofold risk to develop MS according to a recent meta-analysis (Handel et al. 2010). Those with MS have much greater levels of antibodies against EBNA1 and a particular fragment (amino acids 385-420) (Sundstrom et al. 2009; Sundqvist et al. 2012). A most striking note was found in a nested casecontrol study showing primarily all negative EBNA1 individuals had serologically converted before MS onset (Levin et al. 2010). It should be noted that there seems to be a specific window of time for when EBV infection implies a higher MS risk. Infection during adolescence or later implies an increased risk to develop MS, whereas this is not the case for infection during childhood (Ascherio and Munger 2015). Genetic risk for elevated antiEBNA1 titers has been found to be positively correlated with the development of MS (Zhou 2016), which may be interpreted as further evidence for causality of EBV in MS.

HLA risk genes and IM have been observed to interact synergistically to increase the risk of MS (Sundqvist et al. 2012). An interaction between these genes and anti-EBV titers has also been observed. In the biggest study on this topic, persons who tested positive for HLA-DRB1 15, negative for HLA-A 02, and with high EBNA 385-420 IgG titers had a 16-fold higher risk for MS than those who did not carry any of these factors (Sundqvist et al. 2012). Likewise, a pattern of interaction in relation these HLA-risk genes has been observed for smoking and adolescent obesity, respectively (discussed below). As HLA risk alleles encode molecules regulating T-cell adaptive immunity, interaction with measures of EBV infection might show common pathogenetic pathways triggering MS. This is also applicable for recently observed interactions between a history of IM during adolescence and obesity, in which a combination of the two risk factors results in an OR of $\sim 14$ (Hedstrom et al. 2015b).

Of interest, EBV-related RNA has been identified in central nervous system (CNS) lymphoid infiltrates (Serafini et al. 2007), although this is only partially replicated in independent studies (Lassmann et al. 2011). Furthermore, $\mathrm{EBV}$ resides latent in $\mathrm{B}$ cells and anti-CD20 treatments have shown success in depleting these cells in MS (Hauser et al. 2008), which for proponents of the EBV hypothesis has provided some support. Numerous different mechanisms could be considered, such as "molecular mimicry," for which parts of the virus elicit an autoimmune response reactive with CNS components or even a direct immune attack on the virus collaterally damaging the CNS. However, uncertainties on the role for EBV in the triggering of MS remain. Also, few suitable experimen- 
tal models have impeded research. EBV is very common also in normal subjects, and increased antibody titers could be the consequence of a poor elimination through cell-mediated immunity of the pathogen. Analogous to observations in the John Cunningham (JC) virus carriage, wherein high antibody titers show a poor control over viral replication, which is, in turn, regulated by the sets of immune genes, particularly class II genes (Sundqvist et al. 2014), the increase humoral antibody reactivity may be a parallel phenomenon to MS predisposing genes or the disease itself. There have been proponents of mass vaccination against $\mathrm{EBV}$, with the end result of possibly preventing MS in the future. But, even if EBV is involved critically, a modestly effective vaccination may drive infection into higher age groups during adolescence, which appears to be an MS-sensitive period for lifestyle and environmental factors, and therefore could have a negative influence on MS prevention. Additional research is needed to clarify the role of EBV in MS before basic issues pertaining to MS care or prevention can be pursued and dealt with.

\section{SMOKING AND ORAL TOBACCO}

Smoking as a risk factor for MS was suggested from a pooled analysis of several small studies that showed an OR of 1.5 (Hawkes 2007; Handel et al. 2011); this finding was later confirmed in a large case-control study (Hedstrom et al. $2009,2013 \mathrm{~b}$ ). There is a clear dose-response relationship, in which the cumulative dose of smoking is related to a risk increase (Ghadirian et al. 2001; Hedstrom et al. 2009). Cotinine levels in sera/plasma $(\geq 10 \mathrm{ng} / \mathrm{mL})$, reflecting smoking in "pre-MS" samples displayed a similar pattern of risk increase (Salzer et al. 2013). Second-hand exposure to smoke has also been associated with increased risk for MS, which suggests that even minor "lung-irritation" may be important (Hedstrom et al. 2011b). If the association is because of nonspecific irritation, one might even consider a factor such as air pollution as a trigger of CNS neuroinflammation, which in fact has received some support recently (Heydarpour et al. 2014), although requiring larger replication studies to be definitive.
One interesting note, in addition to an increased risk of MS, is that smoking also increases the risk of developing neutralizing antibodies against biologics used in treatment of MS, including natalizumab (Hedstrom et al. 2013a) and interferon $\beta$ (Hedstrom et al. 2014e). In addition, smoking is associated to an increased risk of other inflammatory diseases, like rheumatoid arthritis (RA) (Klareskog et al. 2009) and Jo-antibody positive inflammatory myositis (Chinoy et al. 2012). Therefore, lung irritation may activate both immune response to biologics and a number of organ-specific inflammatory diseases.

To distinguish between roles of nicotine from other tobacco constituents that are inhaled in the lung, the Swedish population is suitable because the use of oral tobacco in the form of moist snuff is very common. Oral tobacco (snuff) shows a dose-dependent association with a lessened risk of MS (Hedstrom et al. 2009, 2013c). Nicotine is the primary candidate for such possible protection in view of its action on the $\alpha 7$ subunit of the acetylcholine receptor present on immune cells, dampening receptor activity (Nizri et al. 2009). This observation underscores the idea that lung inflammation in and of itself drives increased risk.

Smoking provokes lung inflammation with a proinflammatory profile (Shan et al. 2009). If CNS autoantigenic cells are present, it can be hypothesized that these cells may be activated to attack the CNS. There exists experimental evidence for such a scenario. In animal models for MS, experimental autoimmune encephalomyelitis (EAE), encephalitogenic cells become licensed in the lung to acquire a migratory phenotype, allowing immune attack against the CNS. Furthermore, myelin basic protein-specific $T$ cells resident in the lung can be provoked to cause EAE after antigenic challenge through the airways (Odoardi et al. 2012).

Smoking shows a remarkable interaction with MS-associated HLA risk genes. Carriage of the HLA-DRB1*15:01 confers an OR of $\sim 3$, and lack of $H L A-A^{*} 02$ confers an OR of $\sim 1.8$ in the Scandinavian population, resulting in a combined OR of $\sim 5$ among nonsmokers, whereas smokers displayed an OR of $\sim 14$ (Hedstrom et al. 2011c). A similar gene-environment 
interaction has been observed between environmental tobacco exposure (i.e., passive smoking) and the same MS risk HLA genes with regard to MS risk, which can be seen as a replication of the HLA-smoking interaction (Hedstrom et al. 2014a). Additionally, a marked interaction with a variant of non-HLA gene, NAT1 (encodes an enzyme involved in the metabolism of products associated to smoking) has been shown (Briggs et al. 2014). Thus, the effect of smoking is highly dependent on the genetic context and vice versa. Smokers carrying HLA MS risk genes display a considerably higher risk of MS than those without these risk genes (and the risk increase is higher than that from sum of the risk genes alone). It may be argued that this provides an argument for a casual role of these factors because it would be unlikely that HLA genes regulate smoking behavior.

The specific interactions may shine a light on potential disease mechanisms for MS. As discussed above, smoking is also associated with RA although in context with another HLA class II gene (HLA-DRB1*04) (Klareskog et al. 2009), as is polymyositis ( $D R B 1^{*} 03$ ) (Chinoy et al. 2012). These genes code for antigen-presenting molecules, which have different peptide binding preferences. Theoretically, this may be the basis for triggering autoimmune $\mathrm{CD} 4{ }^{+} \mathrm{T}$ cells directed against different organs leading to MS, RA, or myositis, depending on the particular HLA class II molecules carried. Furthermore, it is known that smoking can cause posttranslational modifications of peptides, such as citrullination (Klareskog et al. 2009). Such an event may cause a bypass of central thymic tolerance as a further step in inducing autoimmunity. Interpreting the protective association of $H L A-A^{*} 02$ in MS is more challenging. The role for $\mathrm{CD}^{+} \mathrm{T}$ cells supports histochemical studies of MS brain lesions, where, in fact, $\mathrm{CD}^{+}$dominates over $\mathrm{CD} 4^{+}$ cells. Class I molecules present antigen to $\mathrm{CD} 8^{+}$ T cells and they can be cytotoxic, but also convey suppressor functions through production of molecules like transforming growth factor (TGF)- $\beta$ (for a review on $\mathrm{CD}^{+} \mathrm{T}$ cells in MS, see Friese and Fugger 2005; Friese et al. 2008; Dendrou et al. 2015). In fact, a class I allele-specific suppression mediated by $\mathrm{CD}^{+}$cells and
TGF- $\beta$ has been shown in EAE (Mustafa et al 1993, 1994; Issazadeh et al. 1997).

The smoking data also have practical implications. Based on data in Sweden, 20.4\% of all MS cases were estimated to be attributed to active or passive smoke exposure. For those carrying the genetic $H L A-D R B 1^{*} 15$ risk factor, but lacking $H L A-A^{*} 02,41 \%$ of the MS cases were attributable to smoking (Hedstrom et al. 2016c). From a public health perspective, smoking and passive smoking impacts on MS risk is therefore considerable. Therefore, it is essential that preventive measures be put in place to reduce tobacco smoke exposure. In particular, those with a family history of MS should be informed regarding the impact of smoking on the risk of MS, and the importance of not only preventing their children from being exposed to passive smoke but also not to become smokers. In addition, smoking aggravates disease course in MS (Hernan et al. 2005; Di Pauli et al. 2008; Healy et al. 2009; Pittas et al. 2009; Zivadinov et al. 2009; Manouchehrinia et al. 2013, 2014; Correale and Farez 2015).

Past smoking is also associated with a worsened prognosis in MS (Sundstrom and Nystrom 2008). Because the disease course is aggravated up on continued smoking after diagnosis (Ramanujam et al. 2015) and risk to develop neutralizing antibodies to biologics used for the treatment of MS, there are strong reasons to advise individuals with MS to quit smoking.

\section{SUN EXPOSURE/VITAMIN D}

There are large numbers of studies on sun exposure/vitamin $\mathrm{D}$, provoked by epidemiologic observations of a latitude-dependent difference in MS incidence and prevalence (Koch-Henriksen and Sorensen 2010; Simpson et al. 2011), despite being confounded by the distribution of the HLA DRB1*15:01 risk predisposing genotype in gradients. We recommend the reader to additional comprehensive reviews on the topic (Munger et al. 2014; Lucas et al. 2015).

We depend on ultraviolet radiation (UVR) to convert vitamin $\mathrm{D}$ to an active metabolite; thus it is difficult to distinguish the effect from UVR from that of vitamin $\mathrm{D}$, and vice versa. Both these 
exposures have been related to a decreased risk of MS, as recently and extensively reviewed (Lucas et al. 2015). A higher degree of UVR exposure is related to a decreased risk of MS (Kampman et al. 2007; Simpson et al. 2011; Baarnhielm et al. 2012). Correcting for vitamin D levels, there was still an association of UVR exposure habits on the risk of MS (Baarnhielm et al. 2012), although this finding should be viewed cautiously because vitamin $\mathrm{D}$ levels were not measured before the preclinical phase. The physiological basis of a potential protective effect of UVR is not yet completely understood. UVR exposure protects against MS independently of vitamin D. When studied in the animal model EAE (Becklund et al. 2010), UVR exposure reduces peripheral inflammation in mice (Rana et al. 2011) with a $\mathrm{T}$ regulatory (Treg) cell activation, and dampening effects on antigen-presenting dendritic cells (Navid et al. 2013; Breuer et al. 2014). Production of cis-uronic acid may be involved in these scenarios (Correale and Farez 2013).

A decreased risk of MS with increasing vitamin D levels, especially before age 20, has been observed (Munger et al. 2006), consistent with later data on supplementation and sun exposure (Bjornevik et al. 2014; Cortese et al. 2015). In addition, a diet rich in vitamin $\mathrm{D}$ containing fatty fish also reduces MS risk in the context of low sunlight exposure (Baarnhielm et al. 2014). We have studied vitamin $\mathrm{D}$ levels during pregnancy in humans using samples obtained at birth, with no observed difference between MS cases and controls, although with quite large confidence intervals (Ueda et al. 2014), in line with studies on EAE in which only adolescent rats (not pregnancy or adult rats) displayed an effect of vitamin D (Adzemovic et al. 2013). However, this finding is not undisputed because mothers sampled during the first trimester who had low vitamin D levels resulted in a twofold increased risk for MS in the offspring (Munger et al. 2016). Of numerous explanations for the different results, variations in the timing of sampling, storing issues, or possible "inherited" behavior differences regarding sun exposure are possible reasons. Of note, epidemiologic studies in Australia of exposure to the sun gave evidence for association between low sun exposure in mothers during the first trimester and risk of MS in their children (Staples et al. 2010). Regardless, it appears that vitamin $\mathrm{D}$ and/or sun exposure is important during a time window within the adolescence period in which the vitamin supplementation might mitigate MS risk to some extent. Vitamin D's role is also supported by genetic information, in which polymorphisms close to a central vitamin D metabolism enzyme CYP27B1 gene are associated with MS (Sundqvist et al. 2010; Beecham et al. 2013). Recent genetic data on a series of genes regulating Vitamin D levels displayed significant effects in two case-control studies. Because the distribution of such gene variants is random, it represents to some extent a form of blinded clinical trial, or Mendelian randomization (Mokry et al. 2015; Gianfrancesco et al. 2017). Interestingly, vitamin D was suggested as a first example of a gene-environment interaction with the greatest MS risk gene, HLA $D R B 1^{*} 15: 01$, based on in vitro studies (Handunnetthi et al. 2010), but this finding has not been reproduced in humans (Baarnhielm et al. 2012).

It is still unknown whether vitamin D and or exposure to sun may also have a strong therapeutic effect once MS is established. Although vitamin $\mathrm{D}$ has been added to conventional therapy as part of numerous studies, its importance is not yet resolved. Importantly, high vitamin D levels are associated with lessening of axonal injury as measured by cerebrospinal fluid (CSF) neurofilament light (Sandberg et al. 2015), and during a $\beta$ interferon trial higher levels of vitamin $\mathrm{D}$ were associated with lower MRI activity and slower disease progression (Ascherio et al. 2014; Fitzgerald et al. 2015).

Vitamin D supplementation is believed to be nontoxic even at very high doses, and at the moment it seems reasonable to conduct large clinical trials in individuals, for example, close relatives, at risk for MS or even recommend supplementation at relatively high doses for all adolescents; vitamin D seems to play a part in a number of diseases, not only MS. Sun exposure recommendations are more difficult because of the risk of developing skin cancer. However, moderate exposure is a fair recommendation.

It is still not settled whether vitamin D supplementation is of benefit in individuals with 
established MS. However, many MS patients are aware of the relationship between vitamin $\mathrm{D}$ and MS risk, and use it, especially during wintertime.

\section{ADOLESCENT OBESITY}

In large cohorts, adolescent obesity in females has been associated with MS (Munger et al. 2009, 2013). We replicated this finding regarding adolescent obesity in both males and females, with an $\mathrm{OR}$ of $\sim 2$, although adult body mass index (BMI) at diagnosis had no influence (Hedstrom et al. 2014d). The association is strongest for a BMI of $>27$, although increased ORs are apparent also at more modest BMI levels. Obesity shows association with risk of pediatric-onset MS (Langer-Gould et al. 2013; Munger et al. 2013). We have also observed that for adult MS, the critical period seems to be during adolescence and not at 10 years of age (Hedstrom et al. 2016b). Largely similar results were recently presented in a Norwegian/Italian study (Wesnes et al. 2015). Additionally, Mendelian randomization studies show that genetic determinants for high BMI are associated with an increased risk of MS, bypassing many potential confounders and bias attributed to reverse causality, providing good support for a causal role for this lifestyle factor (Mokry et al. 2016; Gianfrancesco et al. 2017).

Also, in this case, there is an interaction with MS HLA risk genes; specifically, $D R B 1^{*} 15: 01$ positive and $H L A A^{*} 02$ negative individuals with a high BMI display an OR of $\sim 14$ (Hedstrom et al. 2014d), showing further support for the sharing of biological pathways, as well as support for a causal role of obesity. Still, the mechanistic pathways involved in pathogenesis are still unclear. We consider at minimum three non-mutually exclusive and partly overlapping pathways: (1) Obesity is characterized by a "low grade" inflammation in which increased levels of proinflammatory mediators are produced in the fat tissue (Lumeng et al. 2007; Procaccini et al. 2015). Promotion of T helper (Th)1-biased immune responses and decreased function of Treg cells have been described (Matarese et al. 2005). (2) In the presence of obesity, increased levels of leptin, a mediator connected to proinflammation, are observed (Matarese et al. 2005, 2010). (3) Obesity also leads to decreased bioavailability of vitamin $\mathrm{D}$, in turn with options for a proinflammatory bias (Wortsman et al. 2000). Any of the potential mechanisms may enhance the activation and functional proinflammatory bias of adaptive autoreactive immune cells, which may cause the neuroinflammatory bouts, a sequence of events that is supported by the HLA gene interaction; HLA genes encode the antigen-presenting molecules necessary for activation of $\mathrm{T}$ cells.

The relevance of obesity with regard to a putative immune attack on the CNS is also strongly supported by the observed interaction between EBV/IM and BMI, acting independently of the HLA $D R B 1^{*} 15: 01$ class II risk allele, where each of the two lifestyle/environmental factors results in ORs of $\sim 2$, but approaches 14 when combined (Hedstrom et al. 2015b). The reasons for the interaction remain speculative. Obesity may provide a less good fit immune response against EBV, as obesity is associated with a less apt immune defense against infections in general (Karlsson and Beck 2010; Paich et al. 2013). One might also consider a combined proinflammatory milieu during obesity and the so far undefined actions of EBV connected to MS, exaggerating the risk for neuroinflammation. Our argument is based on the fact that interaction between EBV and obesity, two MS risk factors, takes place with regard to the development of MS, supporting the notion of a causal role for both of them in triggering onset.

In this case, obesity data and MS may have a direct connection with prevention for those who are at high risk for MS, such as children of or other relatives of individuals with MS. It is also of interest with respect to the global obesity epidemic and could be one of the factors of importance for the increased incidence of MS among women worldwide.

\section{OTHER LIFESTYLE/ENVIRONMENTAL FACTORS}

Shift work has been observed to be associated with increased risk and development of autoim- 
mune thyroid disorders (Magrini et al. 2006). We observed the association between shift work and MS in two different studies. We observed that exposure to shift work during adolescence, (i.e., before the age of 20), was associated with MS risk with an OR of $\sim 1.7$ (Hedstrom et al. 2011a). In a recent replication study, the investigators also found significant associations beyond age 20, although not as strong (Hedstrom et al. 2015a).

Studies on the role of alcohol and coffee consumption and MS have been inconsistent. In one such study, there was no impact of caffeine or alcohol on MS risk found (Massa et al. 2013). In two large case-control studies, there was evidence supporting a dose-dependent inverse association between MS and alcohol with ORs in the range of 0.7-0.8 (Hedstrom et al. 2014b). A dose-dependent inverse association has also been described in RA (Kallberg et al. 2009). The current data provide no directives for at-risk individuals to refrain from alcohol.

The association between coffee consumption and MS risk was recently investigated in two independent population-based case-control studies. The MS risk was reduced substantially among those who reported a high coffee consumption exceeding $900 \mathrm{~mL}$ of coffee daily (OR $\sim 0.70$ ). Lower odds of MS with increasing coffee consumption were observed, regardless of whether coffee consumption was at disease onset or 5 or 10 years before disease onset was considered (Hedstrom et al. 2016a). Still, the available data are currently not strong enough to support any recommendations regarding coffee in relation to risk.

\section{CONCLUDING REMARKS}

Lifestyle/environmental factors affecting MS are increasingly defined. Combining genetics and environmental factors have contributed to understanding MS; factors interacting with MS risk genes, primarily HLA risk genes, can be argued to share etiologic pathways underlying the disease, additionally arguing for their action on the immune system. This is applicable to smoking, EBV infection, and adolescent obesity. The mechanism for understanding is in its early stages, although, thus far, the vast majority of defined factors can be traced to effects on the immune system, similar to the genetic predisposing elements, and strongly arguing for a primary role of the peripheral immune system driving MS. Factors that trigger disease can increasingly be incorporated into practical health care and even prevention, in particular for individuals at increased risk for MS, especially if there is a familial aggregation.

\section{ACKNOWLEDGMENTS}

The original studies by T.O. cited herein are supported by the Swedish Research Council, the Knut and Alice Wallenberg Foundation, the AFA Foundation, the Swedish Brain Foundation, and the Margaretha af Ugglas Foundation. L.A. received grants for MS research from the Swedish Research Council, the Swedish Research Council for Health, Working Life and Welfare, and the Swedish Brain Foundation.

\section{REFERENCES}

Adzemovic MZ, Zeitelhofer M, Hochmeister S, Gustafsson SA, Jagodic M. 2013. Efficacy of vitamin D in treating multiple sclerosis-like neuroinflammation depends on developmental stage. Exp Neurol 249: 39-48.

Ahlgren C, Lycke J, Oden A, Andersen O. 2010. High risk of MS in Iranian immigrants in Gothenburg, Sweden. Mult Scler 16: 1079-1082.

Ahlgren C, Oden A, Lycke J. 2012. A nationwide survey of the prevalence of multiple sclerosis in immigrant populations of Sweden. Mult Scler 18: 1099-1107.

Ascherio A, Munger KL. 2015. EBV and autoimmunity. Curr Top Microbiol Immunol 390: 365-385.

Ascherio A, Munger KL, Lunemann JD. 2012. The initiation and prevention of multiple sclerosis. Nat Rev Neurol 8: 602-612.

Ascherio A, Munger KL, White R, Kochert K, Simon KC, Polman CH, Freedman MS, Hartung HP, Miller DH, Montalban X, et al. 2014. Vitamin D as an early predictor of multiple sclerosis activity and progression. JAMA Neurol 71: 306-314.

Baarnhielm M, Hedstrom AK, Kockum I, Sundqvist E, Gustafsson SA, Hillert J, Olsson T, Alfredsson L. 2012. Sunlight is associated with decreased multiple sclerosis risk: No interaction with human leukocyte antigen-DRB1*15. Eur J Neurol 19: 955-962.

Baarnhielm M, Olsson T, Alfredsson L. 2014. Fatty fish intake is associated with decreased occurrence of multiple sclerosis. Mult Scler 20: 726-732. 
Becklund BR, Severson KS, Vang SV, DeLuca HF. 2010. UV radiation suppresses experimental autoimmune encephalomyelitis independent of vitamin D production. Proc Natl Acad Sci 107: 6418-6423.

Beecham AH, Patsopoulos NA, Xifara DK, Davis MF, Kemppinen A, Cotsapas C, Shah TS, Spencer C, Booth D, Goris A, et al. 2013. Analysis of immune-related loci identifies 48 new susceptibility variants for multiple sclerosis. Nat Genet 45: 1353-1360.

Berg-Hansen P, Moen SM, Sandvik L, Harbo HF, Bakken IJ, Stoltenberg C, Celius EG. 2015. Prevalence of multiple sclerosis among immigrants in Norway. Mult Scler 21: 695-702.

Bjornevik K, Riise T, Casetta I, Drulovic J, Granieri E, Holmoy T, Kampman MT, Landtblom AM, Lauer K, Lossius A, et al. 2014. Sun exposure and multiple sclerosis risk in Norway and Italy: The EnvIMS study. Mult Scler 20: 1042-1049.

Breuer J, Schwab N, Schneider-Hohendorf T, Marziniak M, Mohan H, Bhatia U, Gross CC, Clausen BE, Weishaupt C, Luger TA, et al. 2014. Ultraviolet B light attenuates the systemic immune response in central nervous system autoimmunity. Ann Neurol 75: 739-758.

Briggs FB, Acuna B, Shen L, Ramsay P, Quach H, Bernstein A, Bellesis KH, Kockum IS, Hedstrom AK, Alfredsson L et al. 2014. Smoking and risk of multiple sclerosis: Evidence of modification by NAT1 variants. Epidemiology 25: 605-614.

Brodin P, Jojic V, Gao T, Bhattacharya S, Angel CJ, Furman D, Shen-Orr S, Dekker CL, Swan GE, Butte AJ, et al. 2015. Variation in the human immune system is largely driven by non-heritable influences. Cell 160: 37-47.

Brynedal B, Duvefelt K, Jonasdottir G, Roos IM, Akesson E, Palmgren J, Hillert J. 2007. HLA-A confers an HLADRB1 independent influence on the risk of multiple sclerosis. PLoS ONE 2: e664.

Chinoy H, Adimulam S, Marriage F, New P, Vincze M, Zilahi E, Kapitany A, Gyetvai A, Ekholm L, Novota P, et al. 2012. Interaction of HLA-DRB ${ }^{*} 03$ and smoking for the development of anti-Jo-1 antibodies in adult idiopathic inflammatory myopathies: A European-wide case study. Ann Rheum Dis 71: 961-965.

Correale J, Farez MF. 2013. Modulation of multiple sclerosis by sunlight exposure: Role of cis-urocanic acid. J Neuroimmunol 261: 134-140.

Correale J, Farez MF. 2015. Smoking worsens multiple sclerosis prognosis: Two different pathways are involved. $J$ Neuroimmunol 281: 23-34.

Cortese M, Riise T, Bjornevik K, Holmoy T, Kampman MT, Magalhaes S, Pugliatti M, Wolfson C, Myhr KM. 2015. Timing of use of cod liver oil, a vitamin D source, and multiple sclerosis risk: The EnvIMS study. Mult Scler 21: 1856-1864.

Dendrou CA, Fugger L, Friese MA. 2015. Immunopathology of multiple sclerosis. Nat Rev Immunol 15: 545-558.

Di Pauli F, Reindl M, Ehling R, Schautzer F, Gneiss C, Lutterotti A, O'Reilly E, Munger K, Deisenhammer F, Ascherio A, et al. 2008. Smoking is a risk factor for early conversion to clinically definite multiple sclerosis. Mult Scler 14: 1026-1030.

Fitzgerald KC, Munger KL, Kochert K, Arnason BG, Comi G, Cook S, Goodin DS, Filippi M, Hartung HP, Jeffery
DR, et al. 2015. Association of Vitamin D levels with multiple sclerosis activity and progression in patients receiving interferon $\beta$-1b. JAMA Neurol 72: 1458-1465.

Friese MA, Fugger L. 2005. Autoreactive $\mathrm{CD} 8^{+}$T cells in multiple sclerosis: A new target for therapy? Brain 128: 1747-1763.

Friese MA, Jakobsen KB, Friis L, Etzensperger R, Craner MJ, McMahon RM, Jensen LT, Huygelen V, Jones EY, Bell JI, et al. 2008. Opposing effects of HLA class I molecules in tuning autoreactive $\mathrm{CD} 8^{+} \mathrm{T}$ cells in multiple sclerosis. Nat Med 14: 1227-1235.

Gale CR, Martyn CN. 1995. Migrant studies in multiple sclerosis. Prog Neurobiol 47: 425-448.

Ghadirian P, Dadgostar B, Azani R, Maisonneuve P. 2001. A case-control study of the association between socio-demographic, lifestyle and medical history factors and multiple sclerosis. Can J Public Health 92: 281-285.

Gianfrancesco MA, Glymour MM, Walter S, Rhead B, Shao X, Shen L, Quach H, Hubbard A, Jonsdottir I, Stefansson $\mathrm{K}$, et al. 2017. Causal effect of genetic variants associated with body mass index on multiple sclerosis susceptibility. Am J Epidemiol 185: 162-171.

Handel AE, Williamson AJ, Disanto G, Handunnetthi L, Giovannoni G, Ramagopalan SV. 2010. An updated meta-analysis of risk of multiple sclerosis following infectious mononucleosis. PLoS ONE 5: e12496.

Handel AE, Williamson AJ, Disanto G, Dobson R, Giovannoni G, Ramagopalan SV. 2011. Smoking and multiple sclerosis: An updated meta-analysis. PLoS ONE 6: e16149.

Handunnetthi L, Ramagopalan SV, Ebers GC. 2010. Multiple sclerosis, vitamin D, and HLA-DRB1*15. Neurology 74: 1905-1910.

Hauser SL, Waubant E, Arnold DL, Vollmer T, Antel J, Fox RJ, Bar-Or A, Panzara M, Sarkar N, Agarwal S, et al. 2008. B-cell depletion with rituximab in relapsing-remitting multiple sclerosis. N Engl J Med 358: 676-688.

Hawkes CH. 2007. Smoking is a risk factor for multiple sclerosis: A metanalysis. Mult Scler 13: 610-615.

Healy BC, Ali EN, Guttmann CR, Chitnis T, Glanz BI, Buckle G, Houtchens M, Stazzone L, Moodie J, Berger AM, et al. 2009. Smoking and disease progression in multiple sclerosis. Arch Neurol 66: 858-864.

Hedstrom AK, Baarnhielm M, Olsson T, Alfredsson L. 2009. Tobacco smoking, but not Swedish snuff use, increases the risk of multiple sclerosis. Neurology 73: 696-701.

Hedstrom AK, Akerstedt T, Hillert J, Olsson T, Alfredsson L. 2011a. Shift work at young age is associated with increased risk for multiple sclerosis. Ann Neurol 70: 733741.

Hedstrom AK, Baarnhielm M, Olsson T, Alfredsson L. 2011b. Exposure to environmental tobacco smoke is associated with increased risk for multiple sclerosis. Mult Scler 17: 788-793.

Hedstrom AK, Sundqvist E, Baarnhielm M, Nordin N, Hillert J, Kockum I, Olsson T, Alfredsson L. 2011c. Smoking and two human leukocyte antigen genes interact to increase the risk for multiple sclerosis. Brain 134: 653-664.

Hedstrom A, Alfredsson L, Lundkvist Ryner M, FogdellHahn A, Hillert J, Olsson T. 2013a. Smokers run increased 
L. Alfredsson and T. Olsson

risk of developing anti-natalizumab antibodies. Mult Scler 20: 1081-1085.

Hedstrom AK, Hillert J, Olsson T, Alfredsson L. 2013b. Smoking and multiple sclerosis susceptibility. Eur J Epidemiol 28: 867-874.

Hedstrom AK, Hillert J, Olsson T, Alfredsson L. 2013c. Nicotine might have a protective effect in the development of multiple sclerosis. Mult Scler 19: 1009-1013.

Hedstrom AK, Bomfim IL, Barcellos LF, Briggs F, Schaefer C, Kockum I, Olsson T, Alfredsson L. 2014a. Interaction between passive smoking and two HLA genes with regard to multiple sclerosis risk. Int J Epidemiol 43: 1791-1798.

Hedstrom AK, Hillert J, Olsson T, Alfredsson L. 2014b. Alcohol as a modifiable lifestyle factor affecting multiple sclerosis risk. JAMA Neurol 71: 300-305.

Hedstrom AK, Hillert J, Olsson T, Alfredsson L. 2014c. Reverse causality behind the association between reproductive history and MS. Mult Scler 20: 406-411.

Hedstrom AK, Lima Bomfim I, Barcellos L, Gianfrancesco M, Schaefer C, Kockum I, Olsson T, Alfredsson L. 2014d. Interaction between adolescent obesity and HLA risk genes in the etiology of multiple sclerosis. Neurology 82: 865-872.

Hedstrom AK, Ryner M, Fink K, Fogdell-Hahn A, Alfredsson L, Olsson T, Hillert J. 2014e. Smoking and risk of treatment-induced neutralizing antibodies to interferon B-1a. Mult Scler 20: 445-450.

Hedstrom A, Akerstedt T, Olsson T, Alfredsson L. 2015a. Shift work influences multiple sclerosis risk. Mult Scler 21: 1195-1199.

Hedstrom AK, Lima Bomfim I, Hillert J, Olsson T, Alfredsson L. 2015b. Obesity interacts with infectious mononucleosis in risk of multiple sclerosis. Eur J Neurol 22: 578 e38.

Hedstrom AK, Mowry EM, Gianfrancesco MA, Shao X, Schaefer CA, Shen L, Olsson T, Barcellos LF, Alfredsson L. 2016a. High consumption of coffee is associated with decreased multiple sclerosis risk; results from two independent studies. J Neurol Neurosurg Psychiatry 87: 454460.

Hedstrom AK, Olsson T, Alfredsson L. 2016b. Body mass index during adolescence, rather than childhood, is critical in determining MS risk. Mult Scler 22: 878-883.

Hedstrom AK, Olsson T, Alfredsson L. 2016c. Smoking is a major preventable risk factor for multiple sclerosis. Mult Scler 22: 1021-1026.

Hernan MA, Jick SS, Logroscino G, Olek MJ, Ascherio A, Jick H. 2005. Cigarette smoking and the progression of multiple sclerosis. Brain 128: 1461-1465.

Heydarpour P, Amini H, Khoshkish S, Seidkhani H, Sahraian MA, Yunesian M. 2014. Potential impact of air pollution on multiple sclerosis in Tehran, Iran. Neuroepidemiology 43: 233-238.

Hughes AM, Lucas RM, McMichael AJ, Dwyer T, Pender MP, van der Mei I, Taylor BV, Valery P, Chapman C, Coulthard A, et al. 2013. Early-life hygiene-related factors affect risk of central nervous system demyelination and asthma differentially. Clin Exp Immunol 172: 466-474.

Issazadeh S, Kjellen P, Olsson T, Mustafa M, Holmdahl R. 1997. Major histocompatibility complex-controlled protective influences on experimental autoimmune enceph- alomyelitis are peptide specific. Eur J Immunol 27: 1584 1587.

Kallberg H, Jacobsen S, Bengtsson C, Pedersen M, Padyukov L, Garred P, Frisch M, Karlson EW, Klareskog L, Alfredsson L. 2009. Alcohol consumption is associated with decreased risk of rheumatoid arthritis: Results from two Scandinavian case-control studies. Ann Rheum Dis 68: 222-227.

Kampman MT, Wilsgaard T, Mellgren SI. 2007. Outdoor activities and diet in childhood and adolescence relate to MS risk above the Arctic Circle. J Neurol 254: 471-477.

Karlsson EA, Beck MA. 2010. The burden of obesity on infectious disease. Exp Biol Med (Maywood) 235: 14121424.

Klareskog L, Catrina AI, Paget S. 2009. Rheumatoid arthritis. Lancet 373: 659-672.

Koch-Henriksen N, Sorensen PS. 2010. The changing demographic pattern of multiple sclerosis epidemiology. Lancet Neurol 9: 520-532.

Langer-Gould A, Brara SM, Beaber BE, Koebnick C. 2013. Childhood obesity and risk of pediatric multiple sclerosis and clinically isolated syndrome. Neurology 80: 548-552.

Lassmann H, Niedobitek G, Aloisi F, Middeldorp JM. 2011. Epstein-Barr virus in the multiple sclerosis brain: A controversial issue-Report on a focused workshop held in the Centre for Brain Research of the Medical University of Vienna, Austria. Brain 134: 2772-2786.

Levin LI, Munger KL, O’Reilly EJ, Falk KI, Ascherio A. 2010. Primary infection with the Epstein-Barr virus and risk of multiple sclerosis. Ann Neurol 67: 824-830.

Lucas RM, Byrne SN, Correale J, Ilschner S, Hart PH. 2015. Ultraviolet radiation, vitamin $\mathrm{D}$ and multiple sclerosis. Neurodegener Dis Manag 5: 413-424.

Lumeng CN, Bodzin JL, Saltiel AR. 2007. Obesity induces a phenotypic switch in adipose tissue macrophage polarization. JClin Invest 117: 175-184.

Magrini A, Pietroiusti A, Coppeta L, Babbucci A, Barnaba E, Papadia C, Iannaccone U, Boscolo P, Bergamaschi E, Bergamaschi A. 2006. Shift work and autoimmune thyroid disorders. Int J Immunopathol Pharmacol 19: 31-36.

Manouchehrinia A, Tench CR, Maxted J, Bibani RH, Britton J, Constantinescu CS. 2013. Tobacco smoking and disability progression in multiple sclerosis: United Kingdom cohort study. Brain 136: 2298-2304.

Manouchehrinia A, Weston M, Tench CR, Britton J, Constantinescu CS. 2014. Tobacco smoking and excess mortality in multiple sclerosis: A cohort study. J Neurol Neurosurg Psychiatry 85: 1091-1095.

Marrie RA, Yu N, Wei Y, Elliott L, Blanchard J. 2013. High rates of physician services utilization at least five years before multiple sclerosis diagnosis. Mult Scler 19: 11131119.

Massa J, O’Reilly EJ, Munger KL, Ascherio A. 2013. Caffeine and alcohol intakes have no association with risk of multiple sclerosis. Mult Scler 19: 53-58.

Matarese G, Carrieri PB, La Cava A, Perna F, Sanna V, De Rosa V, Aufiero D, Fontana S, Zappacosta S. 2005. Leptin increase in multiple sclerosis associates with reduced number of $\mathrm{CD}^{+} \mathrm{CD} 25^{+}$regulatory $\mathrm{T}$ cells. Proc Natl Acad Sci 102: 5150-5155. 
Matarese G, Carrieri PB, Montella S, De Rosa V, La Cava A 2010. Leptin as a metabolic link to multiple sclerosis. Nat Rev Neurol 6: 455-461.

Mokry LE, Ross S, Ahmad OS, Forgetta V, Smith GD, Goltzman D, Leong A, Greenwood CM, Thanassoulis G, Richards JB. 2015. Vitamin D and risk of multiple sclerosis: A Mendelian randomization study. PLoS Med 12: e1001866.

Mokry LE, Ross S, Timpson NJ, Sawcer S, Davey Smith G, Richards JB. 2016. Obesity and multiple sclerosis: A Mendelian randomization study. PLoS Med 13: e1002053.

Moutsianas L, Jostins L, Beecham AH, Dilthey AT, Xifara DK, Ban M, Shah TS, Patsopoulos NA, Alfredsson L, Anderson CA, et al. 2015. Class II HLA interactions modulate genetic risk for multiple sclerosis. Nat Genet 47: 1107-1113.

Munger KL, Levin LI, Hollis BW, Howard NS, Ascherio A. 2006. Serum 25-hydroxyvitamin D levels and risk of multiple sclerosis. JAMA 296: 2832-2838.

Munger KL, Chitnis T, Ascherio A. 2009. Body size and risk of MS in two cohorts of US women. Neurology 73: 15431550.

Munger KL, Bentzen J, Laursen B, Stenager E, Koch-Henriksen N, Sorensen TI, Baker JL. 2013. Childhood body mass index and multiple sclerosis risk: A long-term cohort study. Mult Scler 19: 1323-1329.

Munger KL, Kochert K, Simon KC, Kappos L, Polman CH, Freedman MS, Hartung HP, Miller DH, Montalban X, Edan G, et al. 2014. Molecular mechanism underlying the impact of vitamin D on disease activity of MS. Ann Clin Transl Neurol 1: 605-617.

Munger KL, Aivo J, Hongell K, Soilu-Hanninen M, Surcel HM, Ascherio A. 2016. Vitamin D status during pregnancy and risk of multiple sclerosis in offspring of women in the Finnish maternity cohort. JAMA Neurol 73: 515-519.

Mustafa M, Vingsbo C, Olsson T, Ljungdahl A, Hojeberg B, Holmdahl R. 1993. The major histocompatibility complex influences myelin basic protein 63-88-induced $\mathrm{T}$ cell cytokine profile and experimental autoimmune encephalomyelitis. Eur J Immunol 23: 3089-3095.

Mustafa M, Vingsbo C, Olsson T, Issazadeh S, Ljungdahl A, Holmdahl R. 1994. Protective influences on experimental autoimmune encephalomyelitis by MHC class I and class II alleles. J Immunol 153: 3337-3344.

Navid F, Bruhs A, Schuller W, Fritsche E, Krutmann J, Schwarz T, Schwarz A. 2013. The Aryl hydrocarbon receptor is involved in UVR-induced immunosuppression. J Invest Dermatol 133: 2763-2770.

Nielsen NM, Jorgensen KT, Stenager E, Jensen A, Pedersen BV, Hjalgrim H, Kjaer SK, Frisch M. 2011. Reproductive history and risk of multiple sclerosis. Epidemiology 22: 546-552.

Nizri E, Irony-Tur-Sinai M, Lory O, Orr-Urtreger A, Lavi E, Brenner T. 2009. Activation of the cholinergic anti-inflammatory system by nicotine attenuates neuroinflammation via suppression of Th1 and Th17 responses. J Immunol 183: 6681-6688.

Odoardi F, Sie C, Streyl K, Ulaganathan VK, Schlager C, Lodygin D, Heckelsmiller K, Nietfeld W, Ellwart J, Klinkert WE, et al. 2012. T cells become licensed in the lung to enter the central nervous system. Nature 488: 675-679.
O'Gorman C, Lin R, Stankovich J, Broadley SA. 2013. Modelling genetic susceptibility to multiple sclerosis with family data. Neuroepidemiology 40: 1-12.

Paich HA, Sheridan PA, Handy J, Karlsson EA, SchultzCherry S, Hudgens MG, Noah TL, Weir SS, Beck MA. 2013. Overweight and obese adult humans have a defective cellular immune response to pandemic H1N1 influenza A virus. Obesity (Silver Spring) 21: 2377-2386.

Pittas F, Ponsonby AL, van der Mei IA, Taylor BV, Blizzard L, Groom P, Ukoumunne OC, Dwyer T. 2009. Smoking is associated with progressive disease course and increased progression in clinical disability in a prospective cohort of people with multiple sclerosis. J Neurol 256: 577-585.

Procaccini C, Pucino V, Mantzoros CS, Matarese G. 2015. Leptin in autoimmune diseases. Metabolism 64: 92-104.

Ramanujam R, Hedstrom AK, Manouchehrinia A, Alfredsson L, Olsson T, Bottai M, Hillert J. 2015. Effect of smoking cessation on multiple sclerosis prognosis. JAMA Neurol 72: 1117-1123.

Rana S, Rogers LJ, Halliday GM. 2011. Systemic low-dose UVB inhibits CD8 T cells and skin inflammation by alternative and novel mechanisms. Am J Pathol 178: 27832791.

Roshanisefat H, Bahmanyar S, Hillert J, Olsson T, Montgomery S. 2012. Shared genetic factors may not explain the raised risk of comorbid inflammatory diseases in multiple sclerosis. Mult Scler 18: 1430-1436.

Rothman KJ, Greenland S, Lash TL. 2008. Concepts of interaction. In Modern epidemiology, 3rd ed. (ed. Greenland S, et al.), pp. 71-83. Lippincott Williams \& Wilkins, Philadelphia, PA.

Salzer J, Hallmans G, Nystrom M, Stenlund H, Wadell G, Sundstrom P. 2013. Smoking as a risk factor for multiple sclerosis. Mult Scler 19: 1022-1027.

Sandberg L, Biström M, Salzer J, Vågberg M, Svenningsson A, Sundström P. 2015. Vitamin D and axonal injury in multiple sclerosis. Mult Scler 22: 1037-1031.

Sawcer S, Hellenthal G, Pirinen M, Spencer CC, Patsopoulos NA, Moutsianas L, Dilthey A, Su Z, Freeman C, Hunt SE, et al. 2011. Genetic risk and a primary role for cell-mediated immune mechanisms in multiple sclerosis. Nature 476: 214-219.

Serafini B, Rosicarelli B, Franciotta D, Magliozzi R, Reynolds R, Cinque P, Andreoni L, Trivedi P, Salvetti M, Faggioni A, et al. 2007. Dysregulated Epstein-Barr virus infection in the multiple sclerosis brain. J Exp Med 204: 2899-2912.

Shan M, Cheng HF, Song LZ, Roberts L, Green L, HackenBitar J, Huh J, Bakaeen F, Coxson HO, Storness-Bliss C, et al. 2009. Lung myeloid dendritic cells coordinately induce $\mathrm{T}_{\mathrm{H}} 1$ and $\mathrm{T}_{\mathrm{H}} 17$ responses in human emphysema. Sci Transl Med 1: 4ra10.

Simpson S Jr, Blizzard L, Otahal P, Van der Mei I, Taylor B. 2011. Latitude is significantly associated with the prevalence of multiple sclerosis: A meta-analysis. J Neurol Neurosurg Psychiatry 82: 1132-1141.

Staples J, Ponsonby AL, Lim L. 2010. Low maternal exposure to ultraviolet radiation in pregnancy, month of birth, and risk of multiple sclerosis in offspring: Longitudinal analysis. BMJ 340: c1640.

Sundqvist E, Baarnhielm M, Alfredsson L, Hillert J, Olsson T, Kockum I. 2010. Confirmation of association between 
L. Alfredsson and T. Olsson

multiple sclerosis and CYP27B1. Eur J Hum Genet 18: 1349-1352.

Sundqvist E, Sundstrom P, Linden M, Hedstrom AK, Aloisi F, Hillert J, Kockum I, Alfredsson L, Olsson T. 2012. Epstein-Barr virus and multiple sclerosis: Interaction with HLA. Genes Immun 13: 14-20.

Sundqvist E, Buck D, Warnke C, Albrecht E, Gieger C, Khademi M, Lima Bomfim I, Fogdell-Hahn A, Link J, Alfredsson L, et al. 2014. JC polyomavirus infection is strongly controlled by human leucocyte antigen class II variants. PLoS Pathog 10: e1004084.

Sundstrom P, Nystrom L. 2008. Smoking worsens the prognosis in multiple sclerosis. Mult Scler 14: 1031-1035.

Sundstrom P, Nystrom M, Ruuth K, Lundgren E. 2009. Antibodies to specific EBNA-1 domains and HLA DRB1*1501 interact as risk factors for multiple sclerosis. J Neuroimmunol 215: 102-107.

Ueda P, Rafatnia F, Baarnhielm M, Frobom R, Korzunowicz G, Lonnerbro R, Hedstrom AK, Eyles D, Olsson T, Alfredsson L. 2014. Neonatal vitamin D status and risk of multiple sclerosis. Ann Neurol 76: 338-346.

Wesnes K, Riise T, Casetta I, Drulovic J, Granieri E, Holmoy T, Kampman MT, Landtblom AM, Lauer K, Lossius A, et al. 2015. Body size and the risk of multiple sclerosis in
Norway and Italy: The EnvIMS study. Mult Scler 21: 388395.

Westerlind H, Ramanujam R, Uvehag D, Kuja-Halkola R, Boman M, Bottai M, Lichtenstein P, Hillert J. 2014. Modest familial risks for multiple sclerosis: A registry-based study of the population of Sweden. Brain 137: 770-778.

Westerlind H, Imrell K, Ramanujam R, Myhr KM, Celius EG, Harbo HF, Oturai AB, Hamsten A, Alfredsson L, Olsson T, et al. 2015. Identity-by-descent mapping in a Scandinavian multiple sclerosis cohort. Eur J Hum Genet 23: 688-692.

Wortsman J, Matsuoka LY, Chen TC, Lu Z, Holick MF. 2000. Decreased bioavailability of vitamin D in obesity. Am J Clin Nutr 72: 690-693.

Zhou Y, Zhu G, Charlesworth JC, Simpson S Jr, Rubicz R, Göring HH, Patsopoulos NA, Laverty C, Wu F, Henders A, et al. 2016. Genetic loci for Epstein-Barr virus nuclear antigen-1 are associated with risk of multiple sclerosis Mult Scler 22: 1655-1664.

Zivadinov R, Weinstock-Guttman B, Hashmi K, Abdelrahman N, Stosic M, Dwyer M, Hussein S, Durfee J, Ramanathan M. 2009. Smoking is associated with increased lesion volumes and brain atrophy in multiple sclerosis. Neurology 73: 504-510. 


\section{$\&_{\mathrm{CSH}}^{\infty} \&$ Cold Spring Harbor

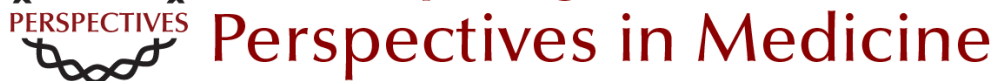

\section{Lifestyle and Environmental Factors in Multiple Sclerosis}

Lars Alfredsson and Tomas Olsson

Cold Spring Harb Perspect Med 2019; doi: 10.1101/cshperspect.a028944 originally published online May 7, 2018

\section{Subject Collection Multiple Sclerosis}

\section{Multiple Sclerosis Pathology} Hans Lassmann

Regulatory T Cells: From Discovery to Autoimmunity Alexandra Kitz, Emily Singer and David Hafler

The Multiple Roles of B Cells in Multiple Sclerosis and Their Implications in Multiple Sclerosis Therapies Rui Li and Amit Bar-Or

Autologous Hematopoietic Stem Cell Transplantation in the Treatment of Multiple Sclerosis Carolina A. Rush, Harold L. Atkins and Mark S. Freedman

B-Cell Therapies in Multiple Sclerosis Joseph J. Sabatino, Jr., Scott S. Zamvil and Stephen L. Hauser

Oral Therapies for Multiple Sclerosis Simon Faissner and Ralf Gold

Interferon $\beta$ for Multiple Sclerosis Dejan Jakimovski, Channa Kolb, Murali Ramanathan, et al.

Alemtuzumab as Treatment for Multiple Sclerosis Serafeim Katsavos and Alasdair Coles

\author{
Natalizumab: Perspectives from the Bench to \\ Bedside \\ Afsaneh Shirani and Olaf Stüve \\ Daclizumab Therapy for Multiple Sclerosis \\ Bibiana Bielekova
}

\section{Lifestyle and Environmental Factors in Multiple Sclerosis Lars Alfredsson and Tomas Olsson \\ Biomarkers in Multiple Sclerosis Anu Paul, Manuel Comabella and Roopali Gandhi}

The Evolving Mechanisms of Action of Glatiramer Acetate Thomas Prod'homme and Scott S. Zamvil

Regulation of Astrocyte Functions in Multiple Sclerosis Michael A. Wheeler and Francisco J. Quintana Experimental Autoimmune Encephalomyelitis (EAE) as Animal Models of Multiple Sclerosis (MS) Simon Glatigny and Estelle Bettelli

Neurodegeneration in Progressive Multiple Sclerosis Graham Campbell and Don Mahad

For additional articles in this collection, see http://perspectivesinmedicine.cshlp.org/cgi/collection/ 